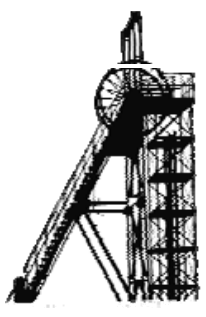

\title{
Aportaciones y enmiendas al artículo "Americanismos en las guajiras flamencas: arte entre dos continentes"
}

\author{
Fernando Cid Lucas \\ Investigador ${ }^{1}$
}

Enviado: $02-06-2020$

Aceptado: $30-11-2020$

\section{Resumen}

En el presente trabajo se amplían y se enmiendan algunas de las informaciones recogidas en el artículo titulado: "Americanismos en las guajiras flamencas: arte entre dos continentes". Con esto se pretende seguir profundizando en el uso de los vocablos llegados desde el continente americano hasta el flamenco $\mathrm{y}$, a su vez, se apuesta por un mejor conocimiento de dichas palabras a la hora de su pronunciación y su recepción en los aficionados o en los estudiosos del flamenco.

Palabras clave: Cuba, décima, flamenco, guajira, repentismo.

\section{Abstract}

This essay expands and revises previous research presented in "Americanisms in the guajiras flamencas: art between two continents" ("Americanismos en las guajiras flamencas: arte entre dos continents"). One of the final aims of this academic review is to offer a better understanding and a deeper explanation of the use of some terms borrowed from the Native American cultures by the 'flamenco' culture. Indeed, a detailed explanation of such terms and their pronunciation will help to shed some light on both amateur and the scholarly studies about flamenco.

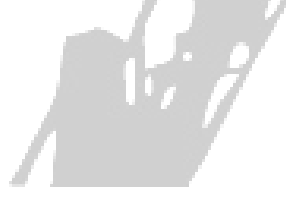

\footnotetext{
${ }^{1}$ Grupo de Investigación "La Recepción del Imaginario Japonés en la Literatura Inglesa y Francesa de Viajes del Siglo XIX", dirigido por la Dra. Lourdes Terrón Barbosa (recuperado de https://www.uatatumi.org/).
} 
A Luca Morganti, en agradecimiento

\section{Introducción}

De sabios es rectificar y se agradece también tener la oportunidad y el lugar para hacerlo. Escribo esto porque en mi artículo titulado "Americanismos en las guajiras flamencas: arte entre dos continentes" (Cid, 2019), cuando en su página número ocho aludía a la interpretación que hace el cantaor José María Valderrama $^{2}$, siguiendo una letra de Federico Alonso Pernía ${ }^{3}$ (que, a su vez, usaba un sustrato popular cubano), extrañaba que en su cante primero negase que el mango fuera de su agrado, pero después afirmase que le gustaba. La letra en cuestión es la que sigue:

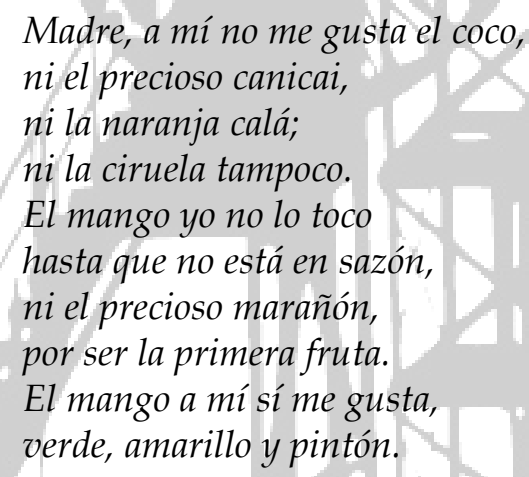

Como afirmaba en mi trabajo, el mundo de los americanismos que se emplean en las guajiras flamencas está todavía por descubrir, se ha estudiado muy poco aún y se muestra como un sendero tortuoso que en un futuro se habrá de recorrer con mayor calma.

Después de darle vueltas y más vueltas, y ya libre del odioso deadline, que siempre oprime más que exhorta, repasando con atención las listas de canciones populares cubanas que guardan la forma de la décima, encontré la fuente de la

\footnotetext{
2 Recuperado de https://www.youtube.com/watch?v=5jGU6wDaO-k.

${ }^{3}$ Recuperado de https://www.youtube.com/watch?v=5jGU6wDaO-k.
} 


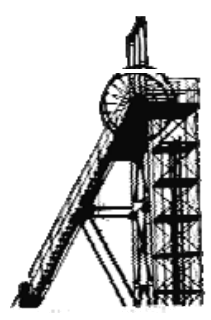

que con toda seguridad bebió Alonso Pernía y que luego varió ligeramente. La letra cubana es como sigue:
A mí no me gusta el coco, ni tampoco el canistel, ni la naranja cajel, ni la de lima tampoco. El mango yo no lo toco si no está en buena sazón, ni el sabroso marañón, que es el rey de todas las frutas. El plátano sí me gusta, verde, amarillo y pintón ${ }^{4}$.

Por tanto, pido disculpas a los lectores, investigadores o aficionados al flamenco por el error cometido. Entono el mea culpa y lamento las molestias que haya podido ocasionar mi imprecisión, reiterando -sin que sirva de excusa- la dificultad a la hora de dilucidar qué es lo que nos llega hoy en las guajiras flamencas que escuchamos y cuáles fueron sus orígenes en la isla del Caribe.

\section{Ahondando en la problemática}

Yo intuía, sin embargo, que encontraría la solución para la misteriosa fruta a la que hacen alusión los versos noveno y décimo. Era cuestión de tiempo y de sentido común. No en vano, en la nota número 30 de mi artículo decía: «No sabemos porqué al inicio de esta guajira al cantante no le gusta esta fruta para afirmar al final de la misma que le gusta de todas las maneras. Tal vez se nos ha "perdido" una fruta tropical con el paso del tiempo y se ha colocado el "mango", de fácil pronunciación, en las dos ocasiones». Y ya está resuelto el enigma. En efecto, el plátano, en las tres variedades que menciona la décima, cuenta con un buen número de recetas en Cuba (el fufú de plátano pintón, carne con plátano pintón, ajiaco cubano, mariquitas, etc.) y ocupa un lugar de

\footnotetext{
${ }^{4}$ Disponible, por ejemplo, en: https://www.cancioneros.com/nc/19502/0/a-mi-no-me-gustael-coco-popular-cubana; o en la bonita versión aflamencada que realizan Silvia Pérez, Alfons Carreras y Cástor Pérez en: https://www.youtube.com/watch?v=8Z6K_vITzFw.
} 
honor en los restaurantes de comida tradicional cubana (también en aquellos abiertos fuera de la isla).

Pero, como propina y sorpresa, descubro que la naranja calá, dulce y sabrosa, a la que canta Valderrama no aparece en la letra cubana, aunque sí la naranja cajel $^{5}$ (o de injerto), que rima a las mil maravillas con el suculento canistel $^{6}$. Supongo yo que fue una solución española dada al defecto de pronunciación en el verso segundo lo que propició, asimismo, la adaptación del tercero.

Es la naranja cajel, por cierto, una fruta que -como mera curiosidad lo añado- aparece descrita en el tomo X-dedicado a la botánica- de la obra del economista y botánico coruñés Ramón Dionisio de la Sagra y Peris (1798-1871) titulada Historia física, política y natural de la isla de Cuba (La Sagra, 1845: 95), por lo que se confirma el conocimiento y la difusión de dicha fruta en Cuba. Y, del mismo modo, la lima injertada del texto original caribeño del verso cuatro aparece transformada en ciruela en la aludida versión de Pernía.

Sin embargo, en defensa de la adaptación de Alonso Pernía, el octavo verso de la décima original no acaba de convencerme del todo, además de por la extensión (9 sílabas $\left.{ }^{7}\right)$, por su ritmo, que me resulta algo "atragantado"; pareciéndome más acorde con el resto de la composición el que usa Valderrama: «por ser la primera fruta», puesto que fluye mejor al cantarse; a no ser que la que transcribo sea una versión adulterada y que el original siguiese la pauta octosilábica con: «el rey de todas las frutas», que no afectaría al significado de la décima.

\footnotetext{
${ }^{5}$ Según el Diccionario de la RAE: «Del catalán catxell. Naranja Cajel o naranja zajarí: 1. f. Variedad de naranja que resulta del injerto del naranjo dulce sobre el borde, y que tiene el gusto agridulce y la corteza interior, así como la pielecilla que divide los gajos de la pulpa, duras y muy tenaces» (recuperado de https:// dle.rae.es/naranja\#M2BL6ty).
}

${ }^{6}$ Pouteria campechiana.

7 Puesto que la décima emplea el octosílabo en sus versos. 


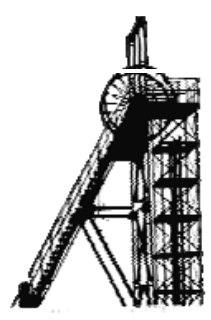

Y otro tanto me parece el verso cuarto, donde aparece la dichosa lima en: «ni la de la lima tampoco», resultando una aliteración demasiado fuerte, tal vez codiciada para los compositores de haikus, pero para la cadencia sensual de la guajira creo que funcionan mejor los acentos del dáctilo de: «ni la ciruela tampoco». Aunque es, repito, una preferencia estilística personal.

Por otro lado, la más críptica de todas las letras de guajiras flamencas que he escuchado hasta el momento parece que, al fin, tiene interpretación. Se nos antoja de difícil comprensión desde esta otra orilla del océano Atlántico, puesto que tiene un sabor muy cubano, está muy ligada a las costumbres de allí y el porcentaje de español o de cultura española es realmente bajo si lo comparamos con lo que tiene de caribeño. Entre otros elementos se incluyen algunas de las señas de identidad más íntimas de la cultura guajira (el sombrero de yarey, los árboles que se citan, etc.). La única interpretación de esta décima que he encontrado hasta ahora es la hecha por el cantaor Manuel Escacena (1886-1928), que yo reproduje en mi trabajo así (Cid, 2019: 29-30):

Ya mí humilde fantasía presume a cada momento, sobre un jobo corpulento comiéndome una jutía. Oiré crujir la varilla, rescatada en el copey y haré que en el babiney el fango mi planta esparza, aunque me rompa una zarza mi sombrero de yarey.

Comencemos nuestra glosa con el esencial (re)descubrimiento de un poeta cubano clave para entender esta y otras letras de guajiras flamencas que aún hoy se cantan, me refiero a Juan Cristóbal Nápoles Fajardo (1829-¿1861?), «el más importante poeta decimista del siglo XIX de Cuba» ${ }^{8}$. Si bien, la mayoría de las guajiras nos han llegado como anónimas, cantadas por los más mayores a los

\footnotetext{
8 Recuperado de https://acento.com.do/2018/opinion/8536371-cucalambe-picaro-seudonimodominicano-poeta-cubano/.
} 
jóvenes, a las que resulta muy difícil seguirles la huella hasta llegar a su origen, perdiéndonos en el camino hacia la fuente, podemos decir, sin temor a equivocarnos, que Nápoles Fajardo es uno de los responsables de la guajira flamenca tal y como hoy la entendemos. Fue dicho escritor cubano el cantor de su tierra, profundamente ligado a la vida de los campos, a sus gentes y quien se apodó a sí mismo como "Cucalambé”, que sería, según algunos estudiosos de su obra, un tipo de baile africano ${ }^{9}$, aunque este significado no está del todo claro.

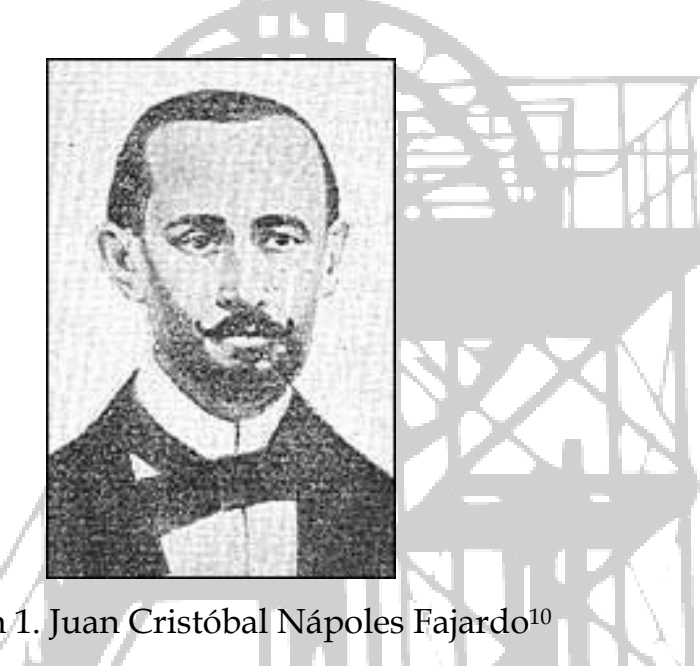

Como digo, Nápoles Fajardo escribió mucho sobre Cuba, tierra por la que sentía un profundo amor. Sorprende el variado léxico que dedica a las labores del campo, a los elementos, a la flora o a la fauna de su país; y es lo que más se le valora, que las palabras que manejaban los agricultores y los ganaderos sirvieran para construir poesía, que las dotase de un valor culto, dignificándolas y haciéndolas válidas para la literatura ${ }^{11}$.

Sus décimas son muy sonoras y expresivas y tuvo mucha repercusión sobre autores de su misma época y posteriores. Tanto fue así que pronto comenzaron a correr sus poemas de boca en boca, variándose con el paso del tiempo, y seguramente por esta vía acabaron en el mundo del flamenco. Como

\footnotetext{
${ }^{9}$ Según otras versiones, el mote sería la unión de dos vocablos: cuca: el órgano sexual femenino; y lambé: una deformación criolla del verbo lamer, realizándose un pícaro juego de palabras.

${ }^{10}$ Recuperado de http://bdigital.bnjm.cu/index.php?secc=autores1.

${ }^{11}$ Recuperado de http://librinsula.bnjm.cu/secciones/241/expedientes/241_exped_1.html.
} 


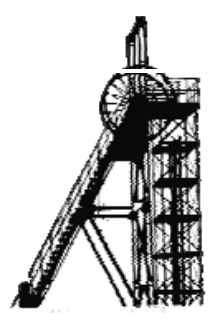

muestra, dejo una de sus décimas incluidas en una composición mayor titulada “A Rufina (desde una ciénaga)" de su poemario Rumores del Hórmigo (Nápoles Fajardo, 1856/1938: 126) como guante lanzado a los cantaores o cantaoras que quieran recogerlo para sumarla a su repertorio al compás de la guajira flamenca:
Aquí, mi prenda querida, de esta ciénaga en el centro, gratos solaces encuentro y paso alegre la vida. Aqui se ve entretejida la verde y silvestre grama, el agua que se derrama. forma dúlcidos rumores, $y$ ostenta variadas flores la ensenada de Virama ${ }^{12}$.

De que Nápoles Fajardo fue un hombre culto no tenemos la menor duda, de que tuvo una buena formación humanística tampoco. Vino al mundo en el seno de una familia en la que se apreciaba la lectura y la escritura, siendo su padre y su hermano aficionados también a la poesía. Tuvo a su alcance una nutrida biblioteca en la que estaban presentes los clásicos griegos y latinos, aunque su preferencia a la hora de elegir sus argumentos fuese siempre la vida de los trabajadores del campo cubano. Y aunque escribió mucho (teatro, poesía, crónicas periodísticas...) murió joven y en unas circunstancias aún desconocidas, ya que desapareció sin dejar rastro a finales de 1861, sin que nunca se encontrase su cuerpo. Varios investigadores afirman que pudo haberse suicidado, pero lo cierto es que no existe prueba fehaciente alguna para poder afirmar esta teoría ${ }^{13}$.

\footnotetext{
${ }^{12}$ Ensenada que se encuentra en las proximidades de Las Tunas, lugar de origen de nuestro poeta. Recuperado de http:// bdigital.bnjm.cu/index.php?secc=autores1.

${ }^{13}$ Según otras versiones, podría haber viajado ocultando su identidad hasta la vecina República Dominicana, donde pudo haber entrado en contacto con otros hombres de letras, como el poeta Juan Antonio Alix (1833-1918), el denominado "Decimero de Moca", y allí habría pasado el resto de sus días.
} 
Pero, volviendo a la décima misteriosa a la que antes aludía, la que se incluyó en el repertorio de la guajira flamenca sin duda por la difusión que conoció la obra de Nápoles Fajardo en su país, esta es su letra:

Ya mi ardiente fantasía
presume a cada momento
sobre un jobo corpulento
ver comiendo una jutía:
Oiré crujir la baría
recostada en el jagüey,
y haré que del babiney
el fango mi planta esparza,
aunque me rompa una zarza
mi sombrero de yarey14.

Ahora, conociendo la existencia, la vida y la obra del poeta cubano, podemos no sólo comprender la enigmática décima a la que nos hemos referido -y que en mis sueños se me aparecía como el arcano Soneto en -x de Stéphane Mallarme-, sino que cobran/sentido otras guajiras que aún hoy se siguen cantando.

La varilla subrayada no es tal, sino la varía, baría, o varía prieta, que es un árbol de tronco relativamente fino, común en toda Cuba en sus regiones más llanas. Puede llegar a medir hasta treinta metros de altura, por lo que, en días ventosos o de tormenta, es coherente lo que dice su autor de que podría oírla "crujir" ante los embates del viento ${ }^{15}$. El problema es que la varía de Nápoles Fajardo está "recostada en el jagüey ${ }^{16 "}$, y es este otro vocablo guajiro que puede causar confusión al investigador, pues, si bien sirve para definir a las pozas de agua dulce realizadas por los campesinos para que pueda abrevar el ganado, el poeta usa otra de sus acepciones: la de un árbol de tronco muy grueso y fuerte ${ }^{17}$

\footnotetext{
${ }^{14}$ Recuperado de https://www.poresto.net/2019/07/13/ecos-de-mi-tierra-180/.

${ }_{15}$ Recuperado de https://www.ecured.cu/Var\%C3\%ADa_(planta).

16 En plural: "jagüeyes".

17 Perteneciente a la familia de las moráceas.
} 


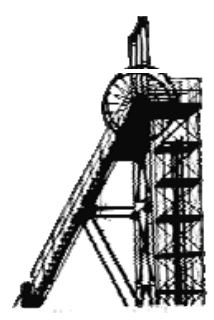

que en las Antillas recibe este mismo nombre y que en Cuba, en concreto, sirve para expresar la ingratitud o la traición, puesto que para que este crezca frondoso y seguro debe apoyarse primero en otro árbol que usa como horquilla/guía, y mientras más crece el jagüey más va ahogándose y consumiéndose el otro árbol, hasta que finalmente muere.

Bella la estampa de la naturaleza salvaje, aunque, por lo que leo en varias páginas de botánica caribeña, más bien sería el tupido jagüey el que se recuesta sobre la pobre varía.

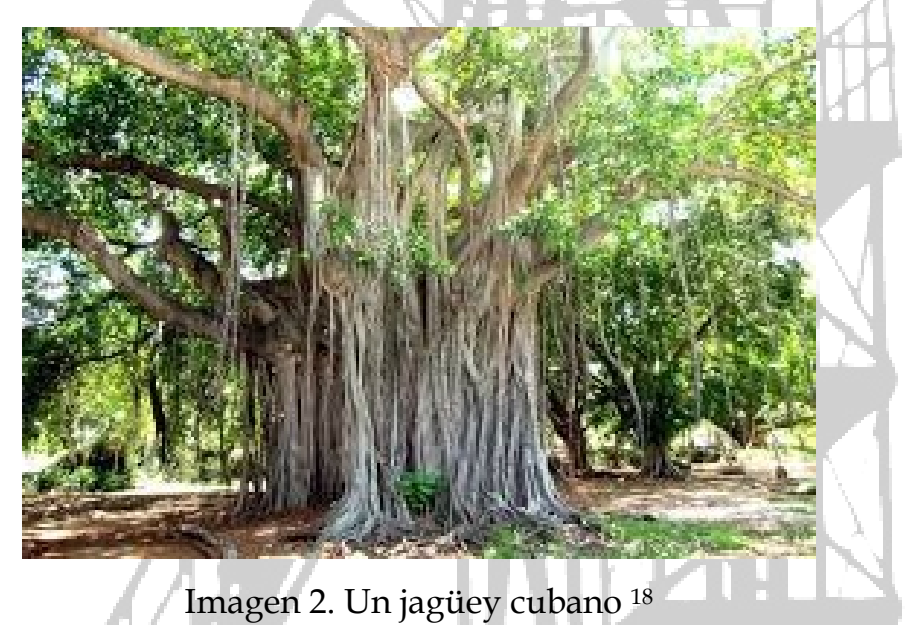

Otra de sus décimas más difundidas dio origen a diversos cantes por guajiras que, en el repertorio flamenco, son, como hace Naranjito de Triana, un collage de procedencia diversa: varias décimas cantadas por prisioneros, una confessio amantis del poeta y algunos versos sobre la preceptiva de la misma guajira, temas que no guardan relación entre sí:

Cuando me sienta "cansao" $y$ de dar voces esté ronco, me sentaré sobre el tronco de algún mamey "colorao", contemplaré "embelesao" la pradera y la colina, y sobre la verde y fina cáscara del mamoncillo, con la punta del cuchillo, pondré el nombre de Rufina.

${ }^{18}$ Recuperado de https://www.todocuba.org/jaguey-arbol-simbolo-ingratitud-traicion/. 
Con este añadido espurio:

Guajirita de mi pensamiento, canta, canta despacito.

La guitarra no ha de rasguear

porque el cante pide puntear ${ }^{19}$.

En cambio, la décima original de Nápoles Fajardo dice así:

Cuando esté de andar cansado

$y$ de vocear esté ronco,

me sentaré sobre el tronco

de algún mamey colorado;

contemplaré embelesado

los guayos de la colina,

y sobre la blanca y fina

cáscara de un anoncillo,

con la punta de un cuchillo

grabaré: "Isabel Rufina"20.

$\mathrm{Ni}$ rastro de los guayos (otra palabra para referirse al mamoncillo o anoncillo) en la versión flamenca. Y esta Isabel Rufina del último verso no es el nombre poético de alguna pastora idealizada, como sucede en la poesía bucólica europea del Barroco y del Neoclasicismo ${ }^{21}$, o un nombre arquetípico de bella mujer, como la Colombina de la Commedia dell'Arte, sino que se corresponde con un nombre real, el de la esposa del poeta, Isabel Rufina Rodríguez Acosta, por lo que la composición tiene un carácter completamente personal.

Como ocurre con la décima que comienza "Ya mi ardiente fantasía...», esta también se encuentra inserta en un poema estructurado en varias décimas que se titula Las monterías. En lo temático parece un poema que no deja de tener un cierto aire épico, en el que un joven (igualado a los héroes de las sagas antiguas) describe su vida en el campo cubano, la persecución -casi obsesiva- de

\footnotetext{
${ }^{19}$ Recuperado de https://www.youtube.com/watch?v=1JrMoScap_8.

${ }^{20}$ Recuperado de https:// www.poresto.net/2019/07/13/ecos-de-mi-tierra-180/.

${ }^{21}$ Véase Domínguez, 2018: 70-84.
} 


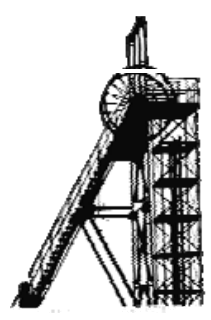

los cerdos cimarrones (o puercos jíbaros), los peligros que entrañan estos animales salvajes, etc., pero donde también encuentra espacio para dedicar algunas estrofas a la contemplación reverencial de la naturaleza o para reflexionar sobre el amor.

\section{Conclusión}

Por todo lo dicho -y finalizo ya este breve artículo con una pequeña reflexión personal- alabo el sabor auténtico de las letras originales cubanas, pero no dejo de verle ciertas virtudes también al fruto madurado en España, como la colaboración entre Federico Alonso Pernía y José María Valderrama, o la valentía de Naranjito de Triana ante un texto tan complicado, puesto que, aún con imprecisiones, no se puede negar la voluntad de buscar un texto cadencioso y honesto formulado a partir de la materia original.

Como comprenderá el lector, lo que tenemos ante nuestros ojos (y nuestros oídos) es lo que sucede con la materia viva del folclore, con la maleable arcilla de la oralidad, siempre cambiante y prevenida para ser versionada. Y de esto los romances, las coplas, las canciones, los trabalenguas o los cuentos populares saben mucho ${ }^{22}$.

Seguramente en el futuro seguirán apareciendo nuevas enmiendas o mejoras a lo que hemos dicho hasta ahora, es justo y beneficioso que sea así. Como decía al inicio de este artículo, este es un camino que está casi por hacer. Tal vez lo importante haya sido haber comenzado, poder dialogar y llegar a dilucidar más letras y a solucionar más problemas a la hora de las interpretaciones de nuestros cantaores y cantaoras. Desde aquí puedo asegurar que esta ha sido, en todo momento, mi única intención, confesando mi amor por el flamenco y por la guajira en particular, por el lugar donde nací y por las

22 Véase, por ejemplo, Ross (1979) y Detienne (1983: 35-58). 
lejanas tierras del Caribe a las que fueron nuestros familiares, hace ya tanto tiempo, en busca de una vida mejor.

\section{Bibliografía}

CID LUCAS, Fernando (2019). Americanismos en las guajiras flamencas: arte entre dos continentes. Revista de investigación sobre flamenco "La Madrugá", n. . 16, pp. 1-37 (recuperado de https:// revistas.um.es/flamenco/article/view/389401/276971).

DetiEnNe, Marcel (1983). L'invenzione della mitologia. Torino: Boringhieri.

DíAZ, Duanel (2005). Los límites del origenismo. Madrid: Colibrí.

DOMÍNGUEZ ROMERO, Elena (2018). La miscelánea poética como narración implícita en el renacimiento inglés. Los casos de England's Helicon (1600-1614). Huelva: Servicio de Publicaciones de la Universidad de Huelva.

LA SAGRA, Ramón de (1845). Historia física, política y natural de la isla de Cuba: Historia. Segunda parte: Historia natural (tomo X, Botánica). Paris: Librería de Arthus Bertrand.

NÁPOles FAJARDO, Juan Cristóbal (1856/1938). Rumores del Hórmigo (corregido, explicado y ampliado por José Muñiz Vergara). La Habana: Talleres de Seonae, Fernández y Ca.

Ross, Elinor Parry (1979). Comparison of Folk Tale Variants. Language Arts, vol. 56, n. ${ }^{\circ} 4$, pp. $422-426$. 